\title{
People and places
}

\section{Opening of the Norah Fry Research Centre}

\author{
V. Raghuraman, Senior Registrar, University of Wales College of Medicine, \\ Department of Psychological Medicine, Ely Hospital, Cardiff
}

A new centre to study the needs of people with learning difficulties (mental handicap) was opened at the University of Bristol on 1 February 1990.

The centre was named after a famous daughter of Bristol, Norah Fry, who spent a significant amount of her life and wealth in improving the quality of life for mentally handicapped people.

The principal interest of the centre is in the development and evaluation of services for people with learning difficulties by both statutory and nonstatutory welfare agencies.

The staff are committed to three fundamental principles:

people with learning difficulties have the same human value as anyone else and the same human rights

living like others within the community is both right and a need

services must recognise the individuality of people with learning difficulties.

Although the centre was declared open formally on 1 February 1990, it has been functioning since 1988 as part of Bristol University's Department of Mental Health. The centre's programme of research is made up of short and long term projects carried out by 11 research staff and two project directors drawn from a range of professional backgrounds. Dr Oliver Russell, Reader, Department of Mental Health, is the Honorary Director of the Research Centre.

The Norah Fry Centre is currently involved in eight projects supported by grants totalling $£ 660,000$ from various agencies. One of the projects which was completed recently is 'An Evaluation of a Community Service for Adults with Learning Difficulties'-a study of the new community service started in Bristol. The second project 'Quality in Action' is a research and development project aimed at the production of a resource pack for managers, staff and consumers to enable them to monitor and improve the quality of their local services. 'The Bristol Advocacy Project' researches into the experiences of people with learning difficulties involved in self and citizen advocacy. All these three projects are funded by the Joseph Rowntree Memorial Trust.

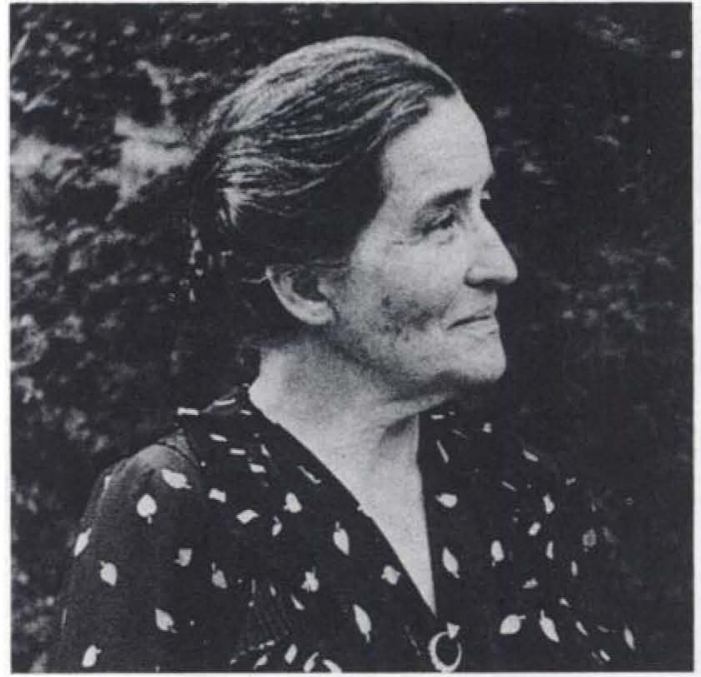

Norah Fry (1871-1960) was the great grand-daughter of Elizabeth Fry, the prison reformer, and Joseph Fry, the founder of the chocolate firm J. S. Fry and Sons Ltd. She was born in Bristol, educated at Newnham College Cambridge and devoted her life to public service in Bristol and Somerset. She was a member of the University Council for 50 years. Norah Fry married Joseph Cooke-Hurle when she was 44 years old. At the end of her life she gave a substantial sum to the University to found the Department of Mental Health. The Norah Cooke-Hurle Chair of Mental Health commemorates her in her married name.

The Department of Health is funding three of their projects: a national study of respite care services called 'Respite Care' which focuses on the needs of the clients who are difficult to place; the study 'Challenging Behaviour' looks into the nature and extent of the problems presented by those showing severely aggressive behaviour; and the third study is an analysis of the primary health care provision in Bristol and Exeter for people being resettled from long-stay institutions. 


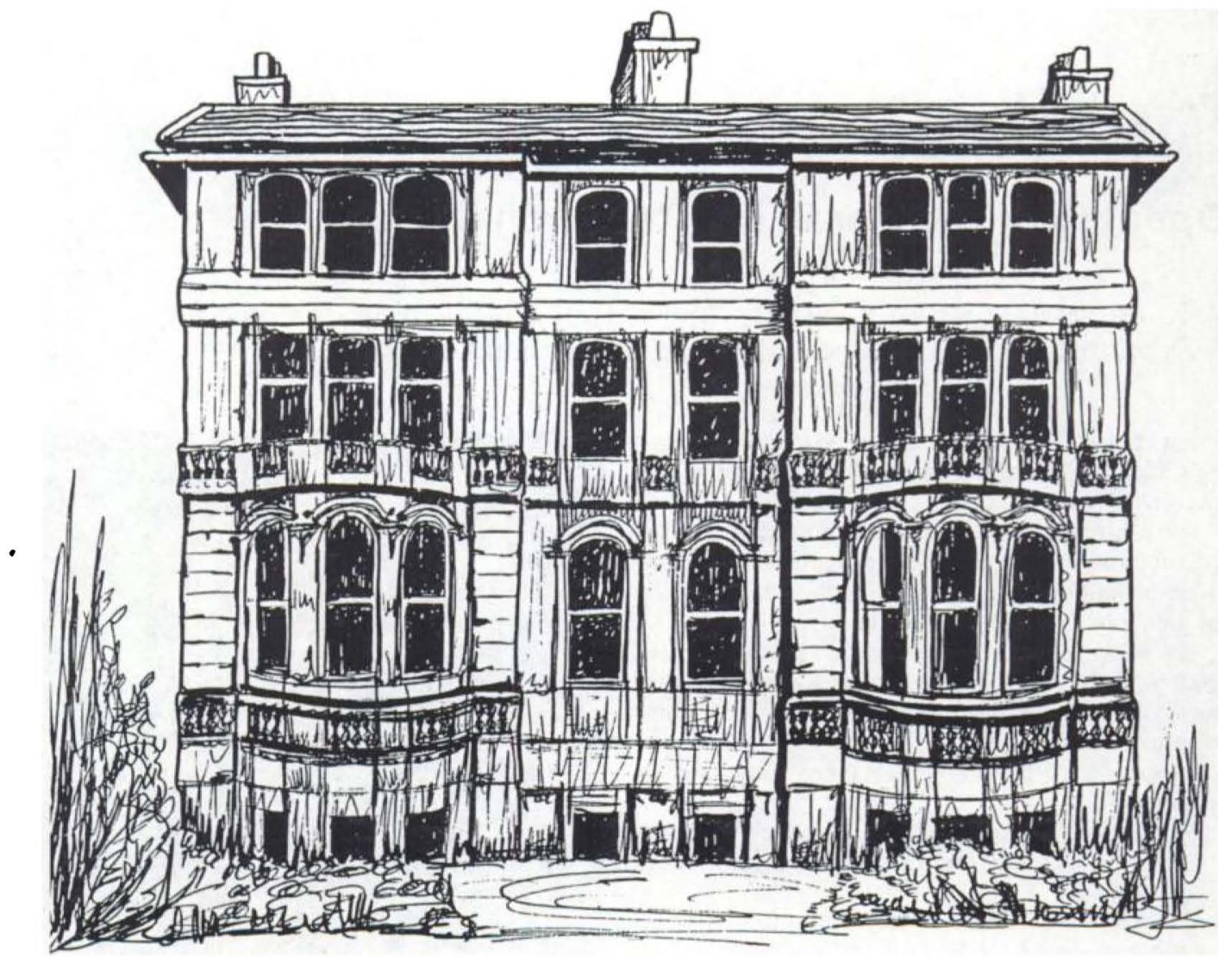

The Norah Fry Research Centre

Another research project, 'Family Based Respite Care', supports the establishment of a national network of family based respite care schemes, and this project is mainly supported by the National Association for Family Based Respite Care with the additional help of the Joseph Rowntree Memorial Trust and the Mental Health Foundation. A project to study the services for people from ethnic minority groups with learning difficulties is being funded by the King Edward's Hospital Fund for London and the Commission for racial Equality, and is called 'Double Discrimination'.

The staff in the Norah Fry Centre wish to expand their services in the future in order to provide consul- tancy, support and advice to agencies and service providers as well as offer training and support to staff and service managers and other professionals.

On the day of its formal opening, there were poster displays of all their present and future projects, and the research staff involved in those projects were helping visitors by explaining these to them.

The Vice Chancellor of Bristol University, Sir John Kingman, FRS, officially declared the centre open after Professor Gethin Morgan, Department of Mental Health, Bristol University, welcomed the gathering. Dr Oliver Russell, Honorary Director of the Research Centre, delivered the vote of thanks. 